và loét da dày.

Tính đến nay (2005-2019) có tổng cộng có 46 nghiên cứu về dupA trên các đối tượng khác nhau. Tập hợp các nghiên cứu này đã khẳng định dupA là một marker gặp nhiều nhất và đặc trưng cho bệnh nhân loét tá tràng, chứ không đặc trưng cho ung thư dạ dày [8]

\section{KẾT LUÂN}

Tỷ lệ cagPAI, oipA, dupA dương tính ở bệnh nhân ung thư dạ dày tương ứng là: 90,3\%, $32,3 \%, 51,6 \%$. Gen cagPAI của $H$. pylori là yếu tố nguy cơ cao gây UTDD tại Việt Nam. Cân nghiên cứu trên số lượng bệnh nhân nhiều hơn.

\section{TÀI LIẸU THAM KHẢO}

1. Yamaoka Y. Mechanisms of disease: Helicobacter pylori virulence factors. Nat Rev Gastroenterol Hepatol. 2010;7(11): 629-641.

2. Maeda S, Yoshida H, Ikenoue $T$, et al. Structure of pathogenicity island in Japanese, Helicobacter pylori, isolates. Gut 1999;44(3): 336-341
3. Ali M, Khan AA, Tiwari SK, et al. Association between cag-pathogenicity island in Helicobacter pylori isolates from peptic ulcer, gastric carcinoma, and non-ulcer dyspepsia subjects with histological changes. World Journal of Gastroenterology 2005; 11(43): 6815-6822

4. Liu J, He $\mathbf{C}$, Chen $\mathbf{M}$, et al. Association of presence/absence and on/off patterns of Helicobacter pylori oipA gene with peptic ulcer disease and gastric cancer risks: A meta-analysis. BMC Infectious Disease 20-13;13: 555-564

5. Braga LLBC, Batista MHR, de Azevedo OGR, et al. OipA "on" status of Helicobacter pylori is associated with gastric cancer in North-Eastern Brazil. BMC Cancer 2019;19(1):48

6. Sterbenc A, Jarc $E$, Polijak $M$, Homan $M$. Helicobacter pylori virulence genes. World Journal of Gastroenterology 2019;25(33): 4870-4884

7. Lu H, Hsu P, Graham DY, Yamaoka Y. Duodenal ulcer promoting gene of Helicobacter pylori. Gastroenterology. 2005;128(4): 833-848.

8. Alam J, Sarkar A, Karmadar BC, et al. Nove virulence factor dupA of Helicobacter pylori as an important risk determinant for disease manifestion: An overview. World Journal of Gastroenterology 2020;26(32): 4739-4752.

\title{
ĐẶC ĐIỂM HÌNH ẢNH VÀ MỨC Độ TỔN THƯƠNG PHỔI TRÊN XQUANG NGỰC Ở BÊNHH NHÂN COVID-19
}

\section{TÓM TẮT}

Mục tiêu: Mô tả đặc điểm hình ảnh và mức độ tổn thương phổi trên Xquang ngực ở bênh nhân COVID-19. Đối tượng và phương pháp: Nghiên cứu mô tả cắt ngang 370 bênh nhân được chẩn đoán dương tính bằng dịch tỵ hầu điều trị tại bệnh viện Trường Đại học Kỹ thuật $Y$ tế Hải Dương. Kết quả: Tổng cộng 370 BN (157nam(42.4\%) và 213 nữ (57.6\%)): tuổi mắc bênh trung bình 34,$74 ;$. Tổn thương thường gặp nhất là tổn thương kính mờ, đông đăc và đạt đỉnh khoảng ngày $5-9$, tổn thương tràn dịch màng phổi, dày màng phổi và giãn phế quản ít gặp $(<1 \%)$, vị trí hay gặp là vùng ngoại vi, tổn thương cả 2 phổi chiếm đa số. Điểm số nghiêm trọng trên Xquang ngực cao nhất là 12 và đỉnh thường phát hiện ở trong 10 ngày đâu của bệnh.

Tư khóa: COVID-19, Thang điểm trầm trọng trên Xquang ngực, Viêm phổi

\section{SUMMARY}

\section{IMAGING CHARACTERISTICS AND}

*Trường Đai hoc Kỹ thuât Y tế Hải Dương

Chịu trách nhiệm chính: Hoàng Văn Hưng

Email: hungleehmu@gmail.com

Ngày nhận bài: 13.5.2021

Ngày phản biên khoa hoc: 6.7.2021

Ngày duyệt bài: 16.7.2021

\section{Hoàng Văn Hưng*, Nguyễn Văn Thắng*, Phạm Thị Thu Thủy*, Trần Văn Việt*}

\section{SEVERITY OF COVID-19 ON CHEST X-RAY}

Purpose: To describe imaging characteristics and severity of COVID-19 on chest X-ray. Material and method: Descriptive cross-sectional study on 370 patients who tested positive for novel coronavirus by nasopharyngeal swap admitted Hai Duong Medical Technical Univesity Hospital. Result: A total of 370 patients (157 (42.4\%) males and 213 (57.6\%) females): mean age is 37.74; The most common finding on chest $x$-rays was peripheral ground glass opacities, consolidation and peaking around 5-9 days, pleural effusion, pleural thickening and bronchiectasis less common, Most of the patients showed bilateral lung affection. The highest severity score recorded was 12 and peak severity score was reached about less than 10 days admit hospital

Keywords: COVID-19, Chest X-ray severity index, Pneumonia

\section{I. ĐẶT VẤN ĐỀ}

Sars-CoV-2 hiện nay là một đại dịch toàn câu gây ảnh hưởng lớn đến các nước trên thế giới. Ca bệnh khởi phát đâu tiên tại thành phố Vũ Hán - Hồ Bắc - Trung Quốc đến nay đã lây lan ra nhiều quốc gia vừng lãnh thổ trên thế giới và đang là thách thức lớn cho toàn thế giới.

Xquang ngực thường ít có giá trị trong chẩn đoán, phát hiện tổn thương giai đoạn nhẹ so với 
CLVT, tuy nhiên lại rất hữu ích trong các giai đoạn từ trung bình đến nặng, trong việc theo dõi tiến triển của bệnh trong bối cảnh dịch bệnh lan rộng và máy Xquang phổ biến, dễ thực hiện ít nhiếm xạ hơn CLVT $[1,2]$.

Hiện tại ở Việt Nam chưa có nghiên cứu nào về tổn thương và mức độ tổn thương phổi do Sars-CoV-2. Nhằm giúp các bác sĩ lâm sàng, dịch tễ và các bác sĩ chẩn đoán hình ảnh có cái nhìn tổng quan về tổn thương phổi do Sars-CoV-2 gây ra và mức độ trầm trọng trên Xquang ngực. Chúng tôi tiến hình nghiên cứu với mục tiêu "Mô tả đặc điểm hinh ảnh và mức độ tổn thương phổ trên Xquang ngực ở bệnh nhân COVID-19".

\section{II. ĐỐI TƯƠNG VÀ PHƯƠNG PHÁP NGHIÊN CỨU}

- Tất cả những BN COVID-19 đã được CDC Hải Dương khẳng định dương tính với Sars-CoV2 bằng phương pháp RT-PCR được cách ly và điêu trị tại BV Đại học Kỹ thuật Y tế Hải Dương từ tháng 1 đến tháng 4 năm 2021 và được chụp xquang ngực.

- Loại trừ những bệnh nhân không có đây đủ thông tin nghiên cứu, không đồng ý tham gia nghiên cứu.

Phim chụp XQ ngực được chia thành ba phân khu:

-Vùng trên: từ đỉnh phổi đến bờ trên cung động mạch chủ

-Vùng giữa: từ bờ trên cung động mạch chủ đến bờ dưới phế quản gốc trái

•Vùng dưới: từ bờ dưới phế quản gốc trái đến cơ hoành

\section{KẾT QUẢ NGHIÊN CỨU}

\subsection{Một số đặc điểm chung.}

Đắc điểm chưng của nhóm nghiên cứu

Bảng 3.1. Phân bố bệnh nhân theo tuổi và giới

\begin{tabular}{|c|c|c|c|c|c|}
\hline \multirow{2}{*}{ Nhóm tuổi Giới } & \multicolumn{2}{|c|}{ Nam } & \multicolumn{2}{|c|}{$\mathbf{N} \tilde{u}$} & \multirow[b]{2}{*}{$\mathbf{p}$} \\
\hline & Tân suất & Tỷ lệ \% & T'ân suất & Tỷ lệ \% & \\
\hline$<20$ & 31 & 8,4 & 32 & 8,6 & 0.049 \\
\hline $20-39$ & 65 & 17,5 & 128 & 34,6 & \\
\hline $40-59$ & 41 & 11,1 & 38 & 10,3 & \\
\hline$\geq 60$ & 20 & 5,4 & 15 & 4,1 & \\
\hline Tổng & 157 & 42,4 & 213 & 57,6 & 0.004 \\
\hline
\end{tabular}

Nhận xét: Tỉ lệ nữ chiếm cao hơn nam với 213 bệnh nhân (57.6\%), sự khác biệt có ý nghĩa thống kê $(p<0,05)$. Tuổi gặp nhiều nhất từ 20-39 tuổi $(32,6 \%)$

\section{2 Đăcc điểm hình ảnh và mức độ tổn thương phổi trên Xquang ngực \\ Các dấu hiệu tổn thương trên XQ ngực \\ Bảng 3.2. Các dâu hiệu tổn thương trên XQ ngực}

\begin{tabular}{|c|c|c|c|c|}
\hline \multirow{2}{*}{ Dâu hiệu trên XQ } & \multicolumn{4}{|c|}{ Tân suất (\%) } \\
\cline { 2 - 5 } & Lần 1(n=370) & Lân 2(n=213) & Lần 3(n=127) & Lân 4(n=166) \\
\hline Nốt mờ & $30(8,1 \%)$ & $19(8,9 \%)$ & $10(7,9 \%)$ & $1(0,6 \%)$ \\
\hline Dày tố chức kẽ & $3(0,8 \%)$ & $2(0,9 \%)$ & $1(0,8 \%)$ & $0(0 \%)$ \\
\hline Đông đặc & $25(6,8 \%)$ & $16(7,5 \%)$ & $6(4,7 \%)$ & $4(2,4 \%)$ \\
\hline Kính mờ & $39(10,5 \%)$ & $31(14,6 \%)$ & $16(12,6 \%)$ & $9(5,4 \%)$ \\
\hline
\end{tabular}

Sau đó mỗi phân khu lại được chia thành hai nửa trái-phải bởi đường kẻ dọc giữa, tương ứng qương kẻ nối gai sau các đốt sống ngực, tổn thương nhu mô phổi được nhân đinh tương ứng ớn bên. Mối bên phôi lại chia thành vùng ngoại vi và vùng trung tâm: kẻ 1 đường thẳng dọc giữa xương đòn mồi bên, vùng ngoại vi được hừ đường kẻ trên ra phía thành ngực (khoảng $1 / 3$ phía ngoài trường phôi), vùng trung tâm tính từ đường kẻ trên vào đường dọc giữa

phân khu sẽ được cho điểm tùy mức độ tổn thương ở mỗi vùng, thang điểm từ 0 đến 3 với gia số 1 điểm cho mỗi mức độ:

- Nhu mô phổi bình thường: 0 điểm

- Tổn thương dạng nốt, dải, <25\%: 1 điểm 50\%: 2 điểm

- Tổn thương rộng, > 50\%: 3 điểm

Mức độ tổn thương phổi được đánh giá là tổng điểm của các vùng, thấp nhất 0 điểm, cao 18 điểm[3] trình điều trị cách ly và được chia ra 4 lần: Lân 1(<4 ngày), lân 2(5-9 ngày), lân 3(10-14 ngày), ân 4 (>15 ngày)

- Số liệu thu thâp sẽ xử lý và phân tích trên phần mềm thống kê SPSS 20.0. Tất cả các biến sẽ được trình bày dưới dạng bảng hoặc biểu đồ. sông (khoảng 2/3 phía trong trường phổi)

- Tổn thương kính mờ hoặc đông đặc nhu mô 


\begin{tabular}{|c|c|c|c|c|}
\hline Giãn phế quản & $1(0,3 \%)$ & $1(0,5 \%)$ & $1(0,8 \%)$ & $1(0,6 \%)$ \\
\hline TDMP & $1(0,3 \%)$ & $1(0,5 \%)$ & $0(0 \%)$ & $0(0 \%)$ \\
\hline Dày màng phối & $0(0 \%)$ & $1(0,5 \%)$ & $0(0 \%)$ & $0(0 \%)$ \\
\hline Không tốn thương & $307(83 \%)$ & $163(76,5 \%)$ & $105(82,7 \%)$ & $156(94 \%)$ \\
\hline
\end{tabular}

Nhận xét: Tốn thương kính mờ, đông đặc chiêm tỉ lệ cao qua các lần chụp đạt đỉnh ở lần chụp 2. Các tổn thương như TDMP, dày màng phổi, giãn phế quản chiếm tỉ lệ rất thấp ở các lần chụp $<1 \%$

Vị trí tổn thương trên Xquang ngực

Bảng 3.3. Vị trí tổn thương

\begin{tabular}{|c|c|c|c|c|c|}
\hline \multirow{2}{*}{ Vị trí trên XQ } & \multicolumn{5}{|c|}{ Tân suất (\%) } \\
\cline { 2 - 6 } & $\begin{array}{c}\text { Lần 1 } \\
(\mathbf{n = 6 7 )}\end{array}$ & $\begin{array}{c}\text { Lần 2 } \\
(\mathbf{n = 5 0 )}\end{array}$ & $\begin{array}{c}\text { Lân 3 } \\
(\mathbf{n = 2 2})\end{array}$ & $\begin{array}{c}\text { Lân 4 } \\
(\mathbf{n = 1 0})\end{array}$ & $\begin{array}{c}\text { Chung } \\
(\mathbf{n = 1 4 9})\end{array}$ \\
\hline Ngoại vi & $64(95,5 \%)$ & $45(90 \%)$ & $20(90,1 \%)$ & $9(90 \%)$ & $138(92,7 \%)$ \\
\hline Quanh rốn phối & $0(0 \%)$ & $1(2 \%)$ & $1(4,5 \%)$ & $0(0 \%)$ & $2(1,3 \%)$ \\
\hline Lan tỏa & $3(4,5 \%)$ & $4(8 \%)$ & $1(4,5 \%)$ & $1(10 \%)$ & $9(6,0 \%)$ \\
\hline Bên phải & $17(25,4 \%)$ & $13(26 \%)$ & $4(18,2 \%)$ & $3(30 \%)$ & $37(24,9 \%)$ \\
\hline Bên trái & $12(17,9 \%)$ & $10(20 \%)$ & $6(27,27 \%)$ & $2(20 \%)$ & $30(20,1 \%)$ \\
\hline Hai bên & $38(56,7 \%)$ & $27(54 \%)$ & $12(54,6 \%)$ & $5(50 \%)$ & $82(55,0 \%)$ \\
\hline
\end{tabular}

Nhận xét: Tốn thương chủ yếu xuất hiện nhu mô vùng ngoại vi, dưới màng phối ở bất cứ giai đoạn nào của bệnh $90-95,5 \%$. Tổn thương phần lớn xuất hiện ở hai phổi $(55 \%)$ tỉ lệ xuất hiện đơn thuần ở phổi phải và trái tương đương nhau.

Mức độ nghiêm trọng trên Xquang ngực

Bảng 3.3. Mức độ inghiêm trọng trên X̛̃uang ngực

\begin{tabular}{|c|c|c|c|c|}
\hline $\begin{array}{c}\text { Điểm nghiêm } \\
\text { trọng }\end{array}$ & $\begin{array}{c}\text { XQ lân 1 } \\
\mathbf{( < 4} \text { ngày) } \\
\mathbf{n = 3 7 0 ( \% )}\end{array}$ & $\begin{array}{c}\text { XQ lân 2 } \\
\mathbf{( 5 - 9} \text { ngày) } \\
\mathbf{n = 2 1 3}(\%)\end{array}$ & $\begin{array}{c}\text { XQ lân 3 } \\
\mathbf{( 1 0 - 1 5} \text { ngày) } \\
\mathbf{n = 1 2 7}(\%)\end{array}$ & $\begin{array}{c}\text { XQ lần 4 } \\
\text { (> 15 ngày) } \\
\mathbf{n = 1 6 6}(\%)\end{array}$ \\
\hline 0 & $304(82.2)$ & $163(76.5)$ & $104(82.5)$ & $156(94)$ \\
\hline 1 & $10(2.7)$ & $6(2.8)$ & $2(1.6)$ & $1(0.6)$ \\
\hline 2 & $11(3)$ & $14(6.6)$ & $9(7.1)$ & $4(2.4)$ \\
\hline 3 & $11(3)$ & $9(4.2)$ & $0(0)$ & $1(0.6)$ \\
\hline 4 & $9(2.4)$ & $5(2.3)$ & $3(2.4)$ & $2(1.2)$ \\
\hline 5 & $11(3)$ & $5(2.3)$ & $0(0)$ & $0(0)$ \\
\hline 6 & $5(1.4)$ & $4(1.9)$ & $3(2.4)$ & $2(1.2)$ \\
\hline 7 & $3(0.8)$ & $3(1.4)$ & $1(0.8)$ & $0(0)$ \\
\hline 8 & $1(0.3)$ & $1(0.3)$ & $1(0.8)$ & $0(0)$ \\
\hline 9 & $0(0)$ & $1(0.3)$ & $1(0.8)$ & $0(0)$ \\
\hline 10 & $3(0.8)$ & $1(0.3)$ & $2(1.6)$ & $0(0)$ \\
\hline 11 & $1(0.3)$ & $0(0)$ & $0(0)$ & $0(0)$ \\
\hline 12 & $1(0.3)$ & $1(0.3)$ & $0(0)$ & $0(0)$ \\
\hline
\end{tabular}

Nhận xét: Phần lớn qua các lần chụp tổn thương phổi trên phim Xquang ghi nhận thấp. Điểm nghiêm trọng lớn nhất là 12 và tổn thưởng chủ yếu ở giai đoạn <10 ngày. Tổn thương nặng ít gặp trên phim chụp xquang phổi sau 15 ngày.

\section{BÀN LUẬN}

4.1 Đặc điểm dịch tễ học. Nghiên cứu tổng số 370BN được nhập viện tại Bệnh viện dã chiến ĐHKTYTHD, chúng tôi thây tỷ lệ nam $(42,4 \%)$, thấp hơn nữ $(57,6 \%)$, sự khác biệt có ý nghĩa thống kê $(p<0.05)$. Nghiên cứu của Monaco và CS[4] cho rằng tî lệ nam/nữ là 2.07/1, trong nghiên cứu của Rabab Yasin tỉ lệ này là 2.93/1. Có sự khác biệt này do sự bùng phát dịch bệnh xảy ra ở khu vựa nào. Khi nghiên cứu vê làn sóng dịch bệnh lần này tại Hải Dương-Việt Nam, chúng tôi thấy dịch bệnh khởi phát và phần lớn có liên quan đến các khu công nghiệp, chủ yếu là công nghiệp nhe vì vậy sự khác biệt về giới cho thấy sự ưu thế ở giới nữ. Ngoài ra, cũng do phần đông bệnh nhân COVID-19 của chúng tôi làm việc tại các khu công nghiệp, ngoài ra nhiều trường hợp có liên quan đên dịch vụ karaoke, giải trí nền qua nghiên cứu chúng tôi thấy rằng lứa tuổi trung bình $34,74 \pm 17,87$, thấp hơn so với tuổi trung bình của bệnh nhân COVID-19 ở hầu hết các nghiên cứu đã̃ từng công bố trước đây. Rabab Yasin (2020)[5] nghiên cứu về hình ảnh tổn thương và diễn biến trên hình ảnh ở 350 bệnh nhân tại Ai Cập cho thấy lứa tuổi dao động 12-81 tuổi, tuổi trung bình 41,68+/- 14,12 tuổi, 
nghiên cứu của Monaco và CS tuổi trung bình là 69 tuổi[4].

\section{2 Đặc điểm hình ảnh và mức độ tổn thương trên Xquang ngực}

Dấu hiệu tổn thương trên Xquang. Trong nghiên cứu này, phần lớn(>75\%) BN COVID-19 không có bất cứ dấu hiệu tổn thương nào được phát hiện trên phim chụp $x$ quang ngực tiểu chuẩn.Trong số những trường hợp được ghi nhận có tổn thương trên phim chụp $x$ quang, chúng tôi thấy các dạng tổn thương thường gặp nhất là kính mờ $(14,6 \%)$, nốt mờ $(8,9 \%)$ và đông đặc nhu mô $(7,5 \%)$ ở lần chụp 2. Các hình thái tổn thương này xuất hiện với tỷ lệ thay đổi ở từng giai đoạn khác nhau của bệnh. Thấp hơn nhiêu so với nghiên cứu của Rabab Yasin và CS (2020) cho thấy dấu hiệu đông đặc nhu mô 218 $\mathrm{BN}(81,3 \%)$, kính mờ $87 \mathrm{BN}(32,5 \%)$, tràn dịch màng phối $(7,5 \%)[5]$. Tuy nhiên nghiên cứu cũng thấy rằng tổn thương kính mờ và đông đặc nhu mô phổi là hay gặp nhất. Có sự khác biệt này là do đối tượng nghiên cứu của chúng tồi bệnh nhân nhập viện với mục tiêu cách ly, điều trị ngay cả khi không có triệu chứng lâm sàng và các chủng mắc là khác nhau. Nghiên cứu của Rousan (2020)[6] thấy rằng tổn thương kính mờ là phổ biến nhất $(55 \%)$ ở ngày $0-5$ của bệnh. Chỉ cố 1 trường hợp tràn dịch màng phổi.

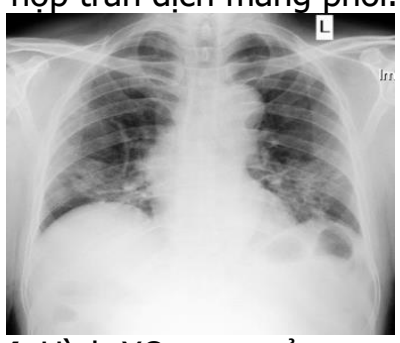

Hình 4.1. Hình XQ ngực của nam BN COVID19, 85 tuổi, mã số 2357 chụp lần 3 sau khởi phát bệnh 12 ngày, trên phim chụp cho thây tổn thương dạng kính mờ kèm giãn phế quản vùng đáy hai phổi với điểm viêm phổi tổng 6 điểm.

Vị trí tổn thương trên Xquang ngực. Hầu hết tổn thương được ghi nhận nằm ở nhu mô vùng ngoại vi, dưới màng phổi (90-95,5\%). Nghiên cứu của Rabab và CS (2020) cũng báo cáo rằng phần lớn tổn thương phân bố ngoại vi (58,2\%)[5]. Nghiên cứu của Rousan (2020) ghi nhận rất ít phát hiện thấy tổn thương vùng trung tâm phổi[6]. Tổn thương phổi do Sars-CoV-2 được ghi nhận trong nghiên cứu này cho thấy, tổn thương xuất hiện trên cả hai trường phổi chiếm đa số (55\%). Như vậy, không có sự ưu thế tổn thương ở bên phổi nào do COVID-19. Nghiên cứu của Rabab và CS (2020), tổn thương xuất hiện ở hai bên chiếm 67,5\%[5]. Theo Rousan (2020) cũng thây rằng tổn thương hai phổi là chiếm ưu thế $30 \%$ [6].

Mức độ trâm trọng trên Xquang ngực. Trong nghiên cứu của chúng tôi điểm nghiêm trọng cao nhất là 12 điểm. Phần lớn được phát hiện ở lần chụp thứ nhất và hai ( $<10$ ngày) sau 15 ngày mức độ nghiêm trọng trên xquang ngực thấp. Nghiên cứu của Rousan(2020) cũng cho rằng điểm nghiêm trọng đạt được vào ngày thứ 5-10 kể từ khi khởi phát[6]. Trái lại Rabab và CS cho rằng tổng mức độ nghiêm trọng cao nhất được tìm thấy ở lần chụp thứ 4 sau 15 ngày. Mức độ nghiêm trọng 5-7 chủ yếu trong giai đoạn 2 và 3 . Có sự khác biệt này là do sự khác biệt về đối tượng nghiên cứu, thang điểm mức độ trầm trọng trên Xquang[5].

\section{KẾT LUÂ̂N}

Sars-CoV-2 chủ yếu gặp ở nữ giới. Tuổi thường gặp 20-39 tuổi.

Tổn thương kính mờ và đông đặc chiếm chủ yếu qua các lân chụp, các tổn thướng giãn phế quản, dày màng phổi, tràn dịch màng phổi hiếm gặp.

Các tổn thương chủ yếu gặp ở ngoại vị với tỉ lệ $>90 \%$ ở các giai đoạn bệnh, vùng rốn phổi rất ít gặp tổn thương. Tổn thương ở hai phổi là đa số (50-56,7\%), tổn thương đơn độc phổi không ưu thế bên phải hoặc trái.

Mức độ tổn thương phổi trên Xquang ngực thấp, chủ yếu điểm nghiêm trọng dưới 5 qua các lần chụp và thường trong vòng 10 ngày đâuu của bệnh.

\section{TÀI LIỆU THAM KHẢO}

1. Cheng, V.C., et al., Severe acute respiratory syndrome coronavirus as an agent of emerging and reemerging infection. Clin Microbiol Rev, 2007. 20(4): p. 660-94.

2. Shi, H., et al., Radiological findings from 81 patients with COVID-19 pneumonia in Wuhan, China: a descriptive study. Lancet Infect Dis, 2020. 20(4): p. 425-434.

3. Borghesi, A. and R. Maroldi, COVID-19 outbreak in Italy: experimental chest X-ray scoring system for quantifying and monitoring disease progression. La Radiologia medica, 2020. 125(5): p. 509-513.

4. Monaco, C.G., et al., Chest x-ray severity score in COVID-19 patients on emergency department admission: a two-centre study. European radiology experimental, 2020. 4(1): p. 68-68.

5. Yasin, R. and $\mathbf{W}$. Gouda, Chest X-ray findings monitoring COVID-19 disease course and severity. The Egyptian Journal of Radiology and Nuclear Medicine, 2020. 51(1): p. 193.

6. Rousan, L.A., et al., Chest $x$-ray findings and temporal lung changes in patients with COVID-19 pneumonia. BMC Pulm Med, 2020. 20(1): p. 245. 